\title{
Analysis of Landslide Block Development Process Using Its Fractal Character
}

\author{
Yoshihiro YOKOI*1, James R. CARR*2 and Robert J. WATTERS*2
}

Key words : fractal, block development process, huge landslide, numerical analysis

\begin{abstract}
We collected data on 39 landslides and analyzed the fractal character of their block distributions and block development process. Correspondence analysis revealed that the fractal dimension correlates to the geometry of the landslide, discontinuities of the base rock, and activity level of the landslide. The fractal dimension is independent of the size of the landslide, angle of slide surface and slope, and geology of the base rock.

The fractal character of landslide block distribution can be explained by self-similar geometry, the unique fractal dimension made by combining second and third level blocks, and the fractal erosional process. The preceding block's geometry influences propagation of subsequent blocks. Lineaments influence the propagation process of second level blocks. As erosion progresses, the fractal dimension decreases. The fractal character of landslide block distribution can be used to identify potential landslides and as a numerical index to describe landslides including their level of activity.
\end{abstract}

\section{Introduction}

Higaki and others ${ }^{1)}$ indicated that the landslide block distribution inside a huge landslide $(>1$ $\mathrm{km}^{2}$ ) has self-similar geometry and that this selfsimilarity can be expressed using a fractal dimension $(D)$. A huge landslide can be classified into first, second, and third level blocks based on the multiple character of landslides ${ }^{2)}$. Yokoi and others ${ }^{3)}$ showed that second and third level blocks also have unique fractal dimensions and the fractal character of landslide block distribution can be explained by: 1) self-similar geometry and 2) unique fractal dimensions made by combining second and third level blocks.

We examined the relationship between the fractal dimension and other properties, e.g., block sizes, geology, etc., using the numerical analysis method. Based on these results, the landslide block development process is discussed.

\footnotetext{
*1 Kiso-Jiban Consultants Co. Ltd., Chugoku Branch

*2 Department of Geological Sciences, Mackay School of Mines, University of Nevada, Reno
}

Data from 39 landslides were used for this study (Appendix). The data were gathered by field investigation, aerial photograph and topographical map interpretation, and literature investigation. Due to the variety of information resources, the accuracy of the data for landslides varies.

\section{Fractal dimensions of landslide block distributions}

We calculated the fractal dimensions of whole blocks (all of first, second, and third level blocks together), second level blocks, and third level blocks from each landslide. The fractal dimension is obtained as the negative slope of the plot of log $(N(r))$ versus $\log (r)$, where $r$ is the ruler length and $N(r)$ is the number of slide-blocks whose width (or length) is greater than the ruler ${ }^{4), 5}$ ).

Figure 1 shows the mean fractal dimension of each level. The mean fractal dimension of second level blocks is $25 \%$ higher than the mean fractal dimension of whole blocks. The mean fractal dimension of third level blocks is more than double the mean fractal dimension of the whole 


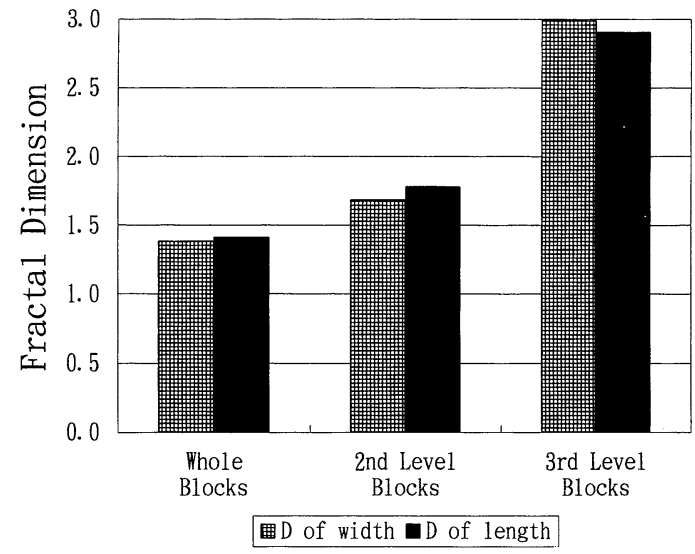

Figure 1 Fractal dimensions of landslide blocks (D: fractal dimension)

blocks. The mean fractal dimension of length of the whole blocks is higher than the mean fractal dimension of width, however, this is not statistically meaningful. The fractal dimension of third level blocks is similar to the fractal dimension of slope failures $\left(D=3.3^{5}\right)$, so this may be due to their common failure mechanics (rotational) and sizes. Fractal dimensions of second and third level blocks are in proportional to each other, as are fractal dimensions of length and width.

\section{Fractal dimensions of lineaments}

The fractal dimension of the lineaments of the base rock in the area next to the 19 landslides was measured (Appendix). In this paper, lineament means any linear feature of the earth's surface, which is interpreted as structural features such as faults, fracture zones, and bedding planes ${ }^{6)}$. The box counting method ${ }^{7)}$ was used to measure the fractal dimensions. The range of mesh size was from $2,000 \mathrm{~m}$ to $62.5 \mathrm{~m}$.

The mean fractal dimension of lineaments is 1.70 and the standard deviation is 0.053 (Appendix). Figure 2 shows the relationship of the fractal dimensions of lineaments and second level blocks (a); and the relationship of the fractal dimensions of lineaments and third level blocks (b). The fractal dimensions of lineaments and length of second level blocks show some correlation (Fig. 2(a)). On the other hand, the fractal dimensions of lineaments and third level blocks show either no correlation or a rather weak inverse relationship (Fig. 2(b)).

\section{What is the fractal dimension of land- slide block distribution?}

In the case of landslide block distribution, the
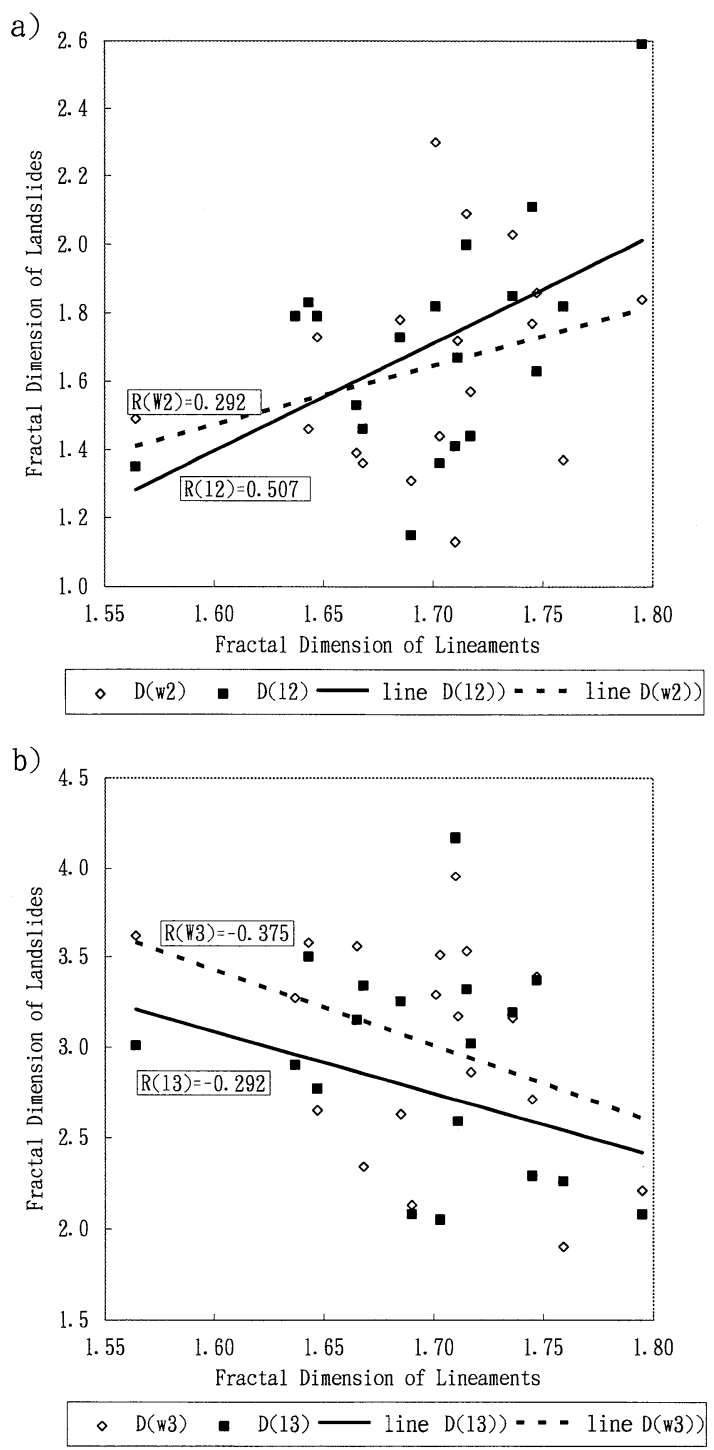

Figure 2 Relationship between the fractal dimensions of lineaments and second level blocks (a) and between those of lineaments and third level blocks (b). $\left(D_{(\mathrm{w} 2)}\right.$ : $D$ of width of second level blocks, $D_{(12)}: D$ of length of second level blocks, $D_{(\mathrm{w} 3)}: D$ of width of third level blocks, $D_{(13)}: D$ of length of third level blocks)

fractal dimension can be expressed in terms of variance. Figure 3 shows the relationship between the logarithms of standard deviation (=square root of variance) and the fractal dimension. They correlate well in inverse. This means that the smaller variance block distribution has the higher fractal dimension and the greater variance block distribution has the lower fractal 

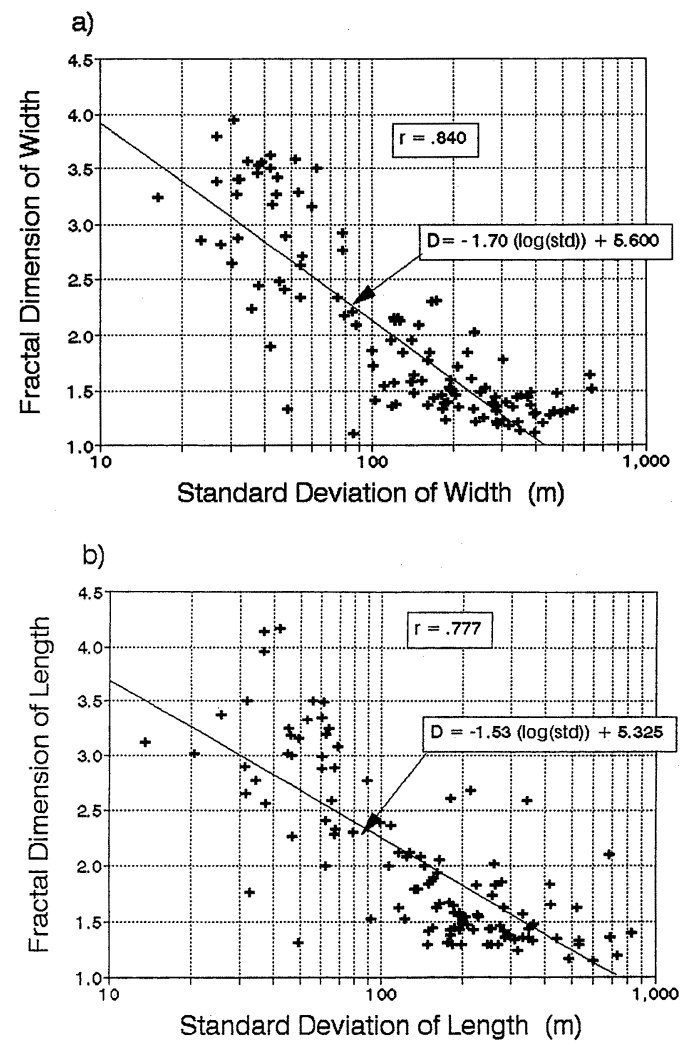

Figure 3 Relationship between fractal dimension and logarithm of standard deviation a) for block width b) for block length.

dimension.

Greater variance means that the size of the blocks' width (or length) has a wider range, so the slope of the $\log (N(r))$ versus $\log (r)$ plot is gentler, which means the fractal dimension is lower. On the other hand, smaller variance means that the size of the blocks' width (or length) is concentrated in a smaller range, so the slope of the $\log (N(r))$ versus $\log (r)$ plot is steeper, which means the fractal dimension is higher (Figure 4).

The most important difference between the fractal dimension and variance is the range of data with which they are calculated. Variance is calculated based on all available data. On the other hand, fractal dimension is calculated based only on data which show fractal character (the straight portion of the $\log (N(r))$ versus $\log (r)$ plot). So data of width (or length) smaller than the fractal character limit don't affect the fractal dimension. Data of width (or length) smaller than the fractal limit is influenced by the accuracy of data collection. Therefore, the fractal dimen- a)

Histogram of number of blocks

$\log [N[r]]$ versus $\log [r]$ plot
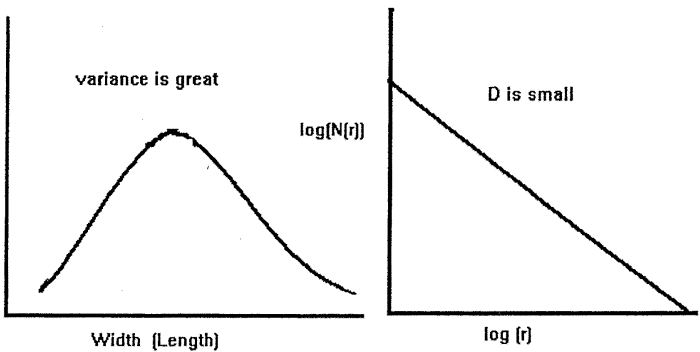

b) Histogram of number of blocks $\log [N(r)]$ versus $\log [r]$ plot

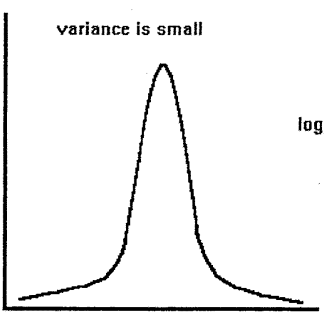

Width [Length]

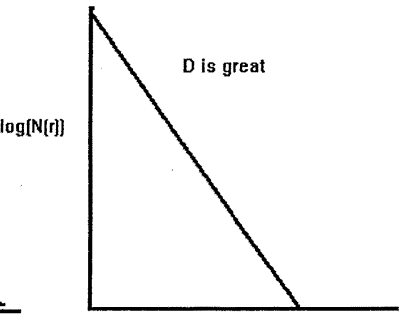

$\log [r]$

Figure 4 Conceptual picture of fractal dimension and variance of landslide blocks. a) When variance is great, fractal dimension is small. b) When variance is small, fractal dimension is great.

sion has an advantage in obtaining the essential characteristics of landslide block distribution by eliminating uncertain data.

\section{Relationship between fractal dimen- sion and other properties}

The relationship between the fractal dimension and other properties was examined. These properties include width, length, area, depth, height, length to width ratio, apparent angle, slide surface angle, apparent dip of base rock, topography, block shape, activity, base rock geology, and geological period of base rock (Table 1).

\section{A) Correspondence analysis}

Correspondence analysis is used for dealing with data which consist of many samples (individuals) and properties (attributes). The results of correspondence analysis are the plots of samples and properties on two dimensional planes whose axes are eigenvectors. The distance between the plots expresses their degree of correlation to each other. In other words, the closer the plots, the more closely they correlate. Correspondence analysis also calculates eigenvalues which tell how much variance the plots represent ${ }^{8)}$. The com- 
Table 1 Definition of properties. (T.: Tertiary)

\begin{tabular}{|c|c|}
\hline Property & Definition \\
\hline Width & maximum separation between right and left flanks \\
\hline Length & distance from crown to mid point of width \\
\hline Area & area of whole landslide \\
\hline Depth & maximum difference between ground level and slide surface \\
\hline Height & difference of level from crown to tip \\
\hline Length to Width ratio & length divided by width \\
\hline Apparent Angle & $\arctan$ (height/length) \\
\hline Apparent Dip & \begin{tabular}{|l} 
apparent dip of base rock in the direction of block sliding \\
Dip Slope (nagare-ban), Horizontal Dip (strike direction slide) \\
Dipping into Slope (uke-ban) \\
\end{tabular} \\
\hline Strike & angle from the direction of block sliding \\
\hline Topography & 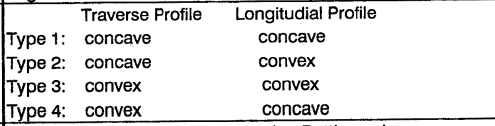 \\
\hline Block Shape & Triangular, Horse-shoe, Rectangular, Bottle-neck \\
\hline Activity & $\begin{array}{l}\text { Fossil: no activity record, blocks are eroded and unclear } \\
\text { Stable: no activity record, clear blocks exist } \\
\text { Dormant: activity record exists, presently inactive } \\
\text { Active: move continuously or intermittently }\end{array}$ \\
\hline Base Rock Geology & $\begin{array}{l}\text { T. mudstone; T. sandstone+mudstone; T. tuff + mudstone; } \\
\text { T. volcanic rock + mudstone; } \\
\text { Mesozoic sedimentary rock; Metamorphic rock }\end{array}$ \\
\hline Geological Period & approximate absolute age of base rock \\
\hline
\end{tabular}

puter software CORSPOND ${ }^{4)}$ was used to perform the analysis. For mathematical and quantitative description of correspondence analysis refer to DAVIS ${ }^{10)}$ or CARR ${ }^{11)}$.

Figure 5 shows the correspondence analysis result for properties. Based on eigenvalue analysis, the plots represent $79 \%$ of the data. From the plots, the properties are classified into three groups and two independents. The groups are properties of size; properties of angle; and properties of geometry and activity. The independents are geology and geological period. The plots suggest that fractal dimension of whole blocks may correlate to properties of geometry (length to width ratio, topography, block shape, apparent dip of base rock) and activity.

\section{B) Fractal dimension and numerical property}

Figure 6 shows the absolute value of the correlation coefficients $r$ between the fractal dimension and each numerical property. By statistical t test, when the following inequation is satisfied, we can tell there is a correlation between the independent variable and dependent variable with a $90 \%$ confidence level ${ }^{12)}$.

$$
\sqrt{\frac{(N-2) r^{2}}{11-r^{2}}}>1.684
$$

where $N$ is the number of samples. In this case, $N$ is 39 and when the inequation is solved:

$$
|r|>0.267
$$

Only the length to width ratio indicates a $90 \%$ confidence level correlation with both the fractal dimension of width and the fractal dimension of
- Geological Period

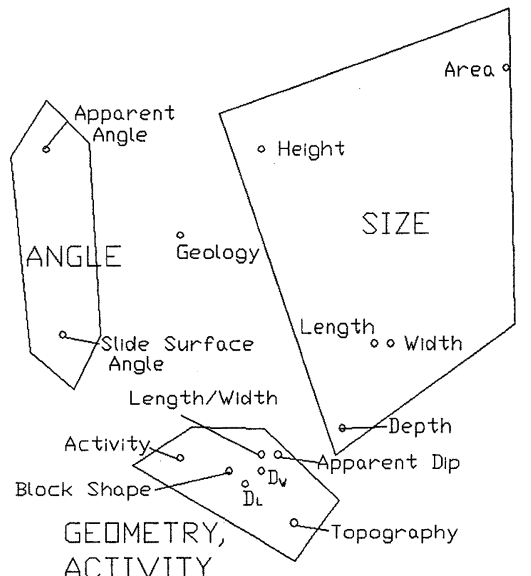

Figure 5 Correspondence analysis plot for properties. The distance between the plots expresses degree of correlation. ( $D_{\mathrm{w}}$ : fractal dimension of width block, $D_{\mathrm{L}}$ : fractal dimension of length of whole blocks)

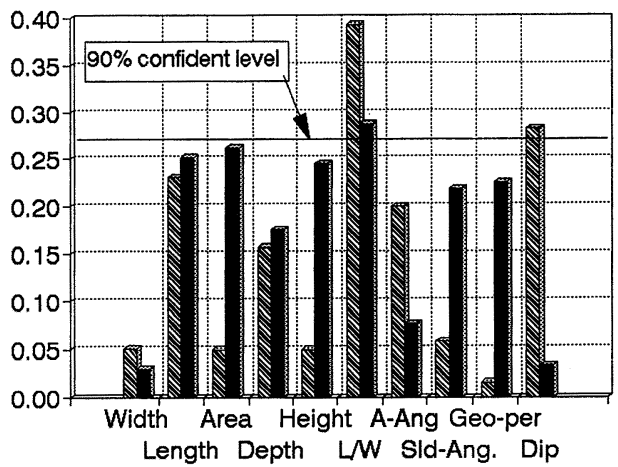

D (Width) D (Length)

Figure 6 Absolute value of correlation coefficient between fractal dimension and other numerical properties. $(L / W$ : length to width ratio, A - Ang : apparent angle, Sld - Ang : slide surface angle, Geo-per : geological period)

length.

\section{C) Interrelation of length to width ratio}

The correspondence analysis suggested that properties of geometry and activity may correlate to fractal dimension. We examined the interrelation between those properties and length to width ratio to find if the correlations are independent or not. Figure 7 shows the relationship between the length to width ratio and the gap between the frac- 
tal dimension of width and the fractal dimension of length of each group classified by topography, block shape, and activity. For topography and block shape data, the gaps are in proportion to the length to width ratio. This suggests that the relationship of the fractal dimension to topography and block shape can be variations of the relationship between the fractal dimension and the length to width ratio. Figure 8 shows the relationship between the length to width ratio and apparent dip. Apparent dip is independent of the length to width ratio.

\section{D) Influence of the properties on fractal dimension}

The previous discussion revealed that the length to width ratio, activity, and apparent dip may influence the fractal dimension. We analyzed the cause of this influence.

a) Length to width ratio

Figure 9 indicates that the slopes of the plots of the length to width ratio versus the fractal dimension of width and of the length to width ratio versus the fractal dimension of length are the inverse of each other. This is a unique phenomenon because basically the fractal dimension of width and length is correlated positively and this inverse relationship can be explained as follows. In a landslide whose width is wide and whose length is short, the variance of width becomes great and the variance of length becomes small. On the other hand, in a landslide whose length is long, the variance of width becomes small and the variance of length becomes great. The fractal dimension is related to variance inversely. So the slopes

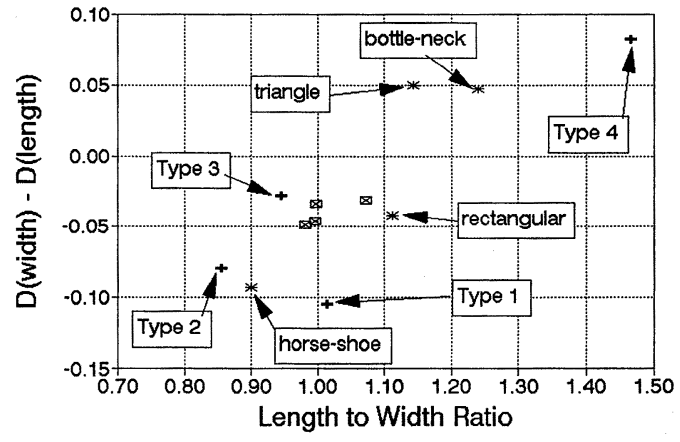

+ topography $*$ block shape $\bowtie$ activity

Figure 7 Reletionship between mean length to width ratio and gap of fractal dimension of width and fractal dimension of length of each group classified by topography, block shape, and activity. of Figure 9 a) and b) are inversions of each other.

b) Apparent dip

Figure 10 shows the mean fractal dimension of dip slope (nagare-ban), horizontal dip, and dipping into slope (uke-ban) landslides. The fractal dimension of dipping into slope landslides is lower than the others. This may suggest that in dip slope landslides, blocks tend to fail along bedding planes; and on the other hand, in dipping into slope landslides, there aren't regular weak bedding planes, so the variance of the blocks becomes greater. The fractal dimension is inversely related to variance. So the fractal dimension of dipping into slope landslides is lower than that of the others.

\section{c) Activity}

Figure 11 shows the mean fractal dimension of each activity level. The positive correlation between activity level and fractal dimensions is clear. This means that the more active the landslide is, the higher the fractal dimension.

The correlation between activity level and the fractal dimension can be explained as follows. The present block distribution is the result of interaction between block propagation and erosion. When block propagation stops, the number of blocks begins to decrease due to erosion. Many small blocks are eroded while far fewer big blocks are eroded. In other words, the absolute value of the slope of $\log (N(r))$ versus $\log (r)$ plot, which is equivalent to the fractal dimension, decreases (Figure 12).

\section{Fractal models of landslide block dis- tribution}

Yokoi and others ${ }^{3)}$ indicated that two kinds of landslide block models, Model A and Model B

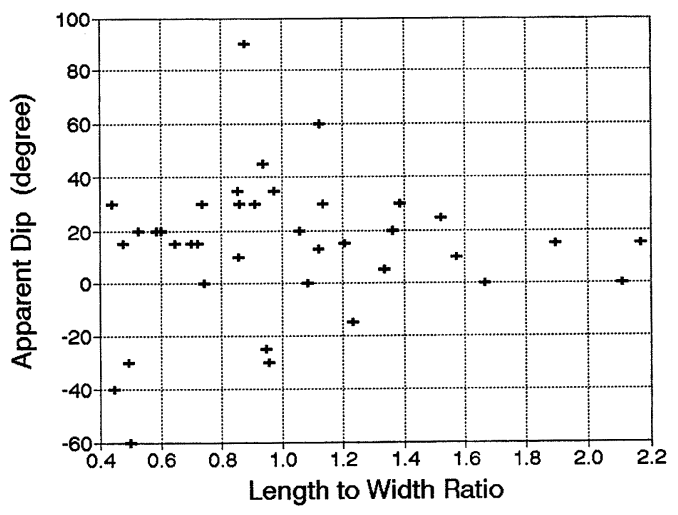

Figure 8 Relationship between apparent dip and length to width ratio. 


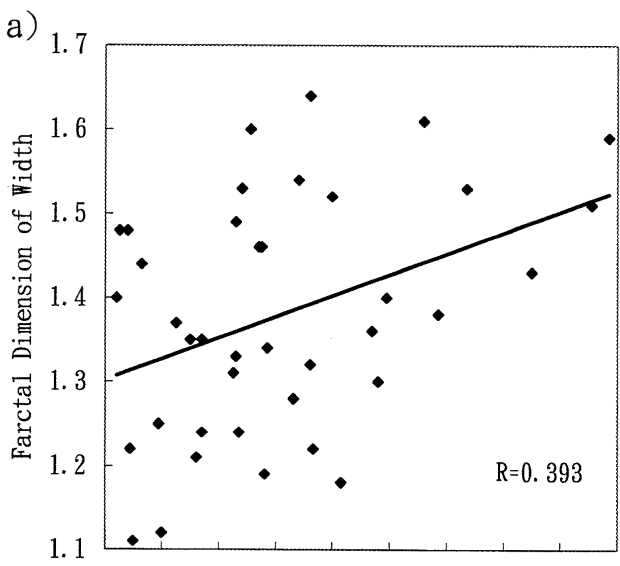

$\begin{array}{lllllllllll}0.4 & 0.6 & 0.8 & 1.0 & 1.2 & 1.4 & 1.6 & 1.8 & 2.0 & 2.2\end{array}$ Length to Midth Ratio

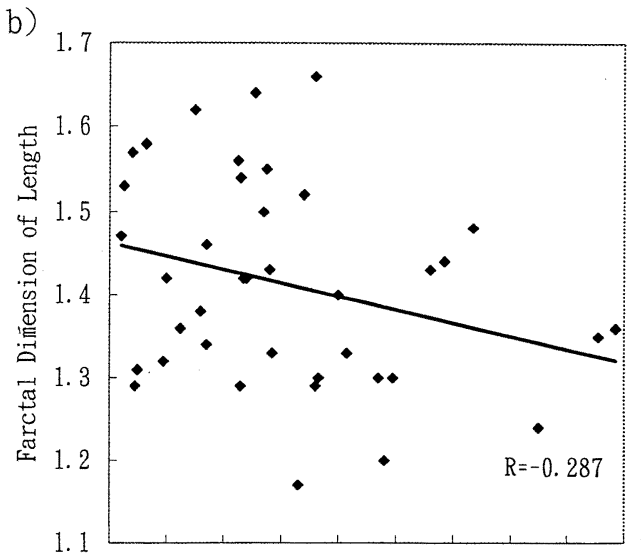

$\begin{array}{llllllllll}0.4 & 0.6 & 0.8 & 1.0 & 1.2 & 1.4 & 1.6 & 1.8 & 2.0 & 2.2\end{array}$ Length to Width Ratio

Figure 9 Relationship between length to width ratio, and a) fractal dimension of width and b) fractal dimension of length.

(Figure 13), help in understanding the fractal character of landslide block distribution. We examined the applicability of the two fractal landslide block models to our actual landslides. For a detailed discussion about the models refer to Yokoi and others ${ }^{3)}$.

\section{A) Model A}

In Model A, a certain number of second level blocks occur in the first level block and the same number of third level blocks occur in each second level block and so on (Figure 13). In other words, Model A is an ideal self-similar landslide. The fractal dimensions of Model A $\left(D_{\text {model } A}\right)$ can be calculated as:

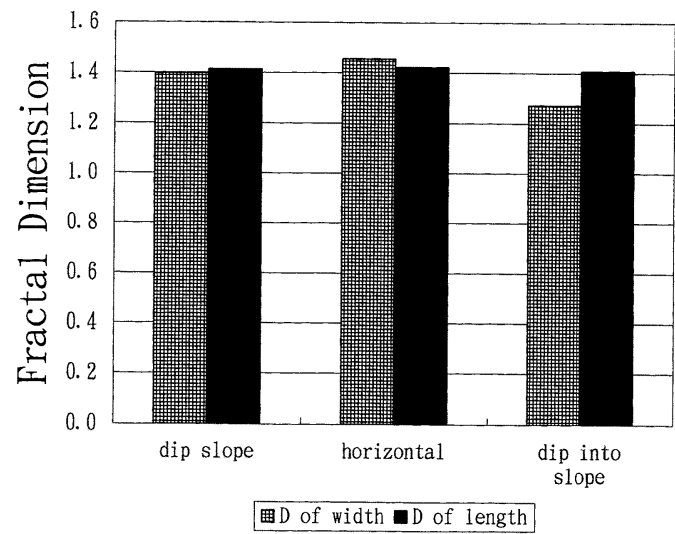

Figure 10 Mean fractal dimension of each dipping type.

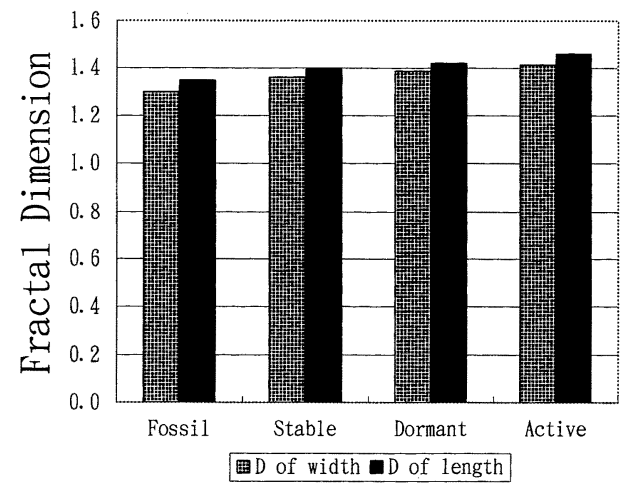

Figure 11 Mean fractal dimension of each activity level.

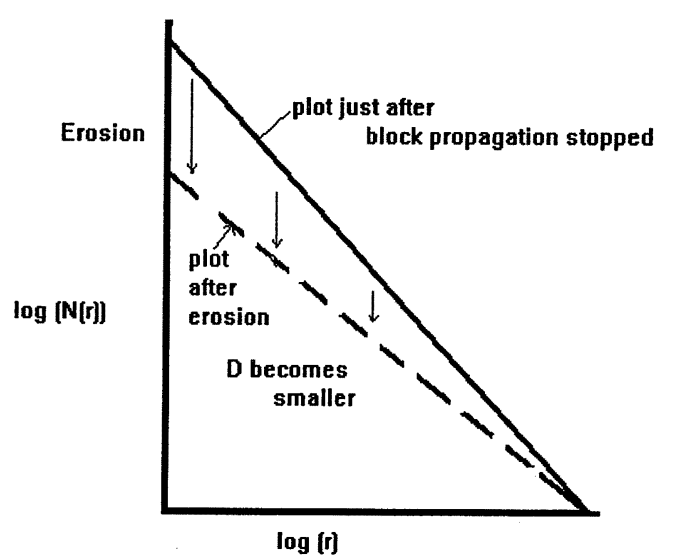

Figure 12 Conceptual illustration of the $\log \left(N_{(r)}\right)$ versus $\log (r)$ plot after block propagation stops. When block propagation stops, the number of blocks begins to decrease due to erosion. Therefore the absolute value of the slope of the plot (=fractal dimension) decreases. 


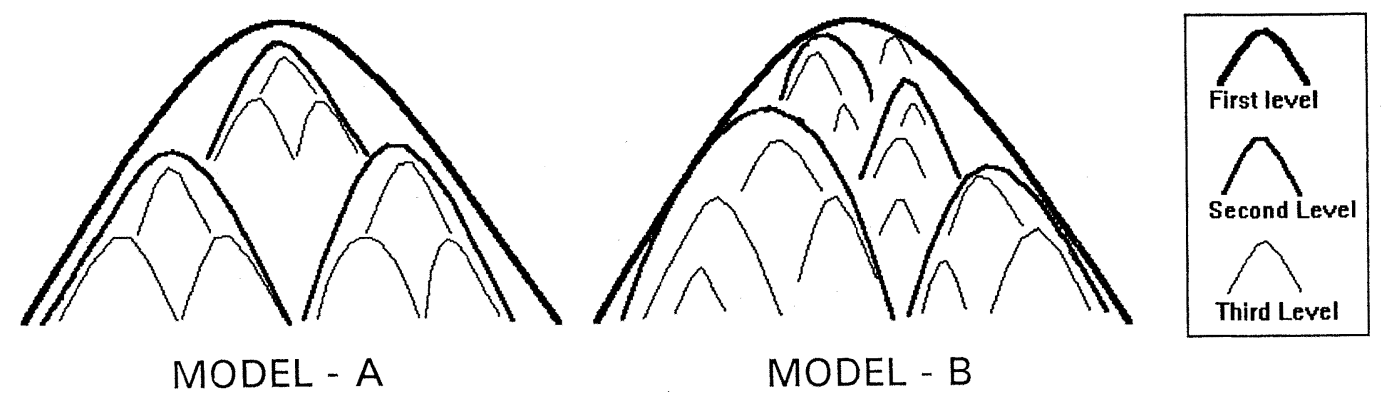

Figure 13 Conceptual illustration of a) Model A and b) Model B. (from Yokoi and others ${ }^{3)}$ )

$$
D_{\text {model } A}=\frac{\log (b)}{\log (1 / s)}
$$

where $b$ is the number of second level blocks inside the first level block; and $s$ is the mean of width (or length) of the second level blocks divided by the width (or length) of the first level block $^{3)}$.

Figure 14 shows the relationship between the actual fractal dimensions and the fractal dimensions of Model A. Their correlation, and the correlation between the length to width ratio and the fractal dimension, suggest that self-similar subsequent blocks develop under the influence of the block geometry of the preceding block.

\section{B) Model B}

In Model B, each of the second level blocks and third level blocks has a unique fractal dimension and the combination of these blocks with the first level block yields another fractal dimension (Figure 13).

When there are $n$ blocks, the theoretical fractal dimension $(D t)$ can be calculated as:

$$
D t=\frac{\log (n)}{\log \left(W_{1}\right)-\log \left(W_{n}\right)}
$$

where $W_{1}$ is the greatest width (or length) and $W_{n}$ is the $n$th block's width (or length). The equation above can be rewritten to become:

$$
W_{n}=10^{\left[\log \left(W_{1}\right)-(\log (n) / D t)\right]}
$$

We calculated the theoretical width (or length) of first, second, and third level blocks using the fractal dimensions of whole, second, and third level blocks as the theoretical fractal dimensions. We combined these blocks with the same number of actual blocks, and plotted the $\log (r)$ $\log (N(r))$ curve and calculated the fractal dimension of Model B as the negative of the slope of the least squares linear regression ${ }^{3)}$.

Figure 15 shows the relationship between the fractal dimension of Model B and the actual dimensions. They correlate to each other positively fairly well. This suggests that the development process of second and third level blocks is diflerent.

\section{Analysis of block development process}

The previous discussion revealed that the fractal dimension of landslide block distribution correlates to the length to width ratio, apparent dip, the fractal dimension of lineaments and activity. The length to width ratio expresses the geometry of the landslide. Dip and the fractal dimension of lineaments are characteristics of discontinuities. Therefore, the fractal dimension of landslide block distribution is essentially influenced by landslide geometry, discontinuities, and activity.

The fact that the fractal dimensions of both Model A and Model B correlate with the actual fractal dimension suggests that the actual landslide block distribution has characteristics of both Model A and Model B. In other words, the landslide block develops self-similarly, while at the same time, second and third level blocks develop independently and combined blocks come to have a self-similar character ${ }^{3)}$.

The present block distribution is the result of interaction between block propagation and erosion. As discussed previously, activity controls the time period of erosion, and geometry and discontinuities control the block propagation process. The self-similar (fractal) characteristics of landslide blocks can be explained by the influence of block geometry on block propagation. Under the influence of block geometry, selfsimilar subsequent blocks develop inside the preceding block. This process is idealized in Model A.

Dip expresses the characteristics of discontinuities. The correlation between dip and the fractal 
a)

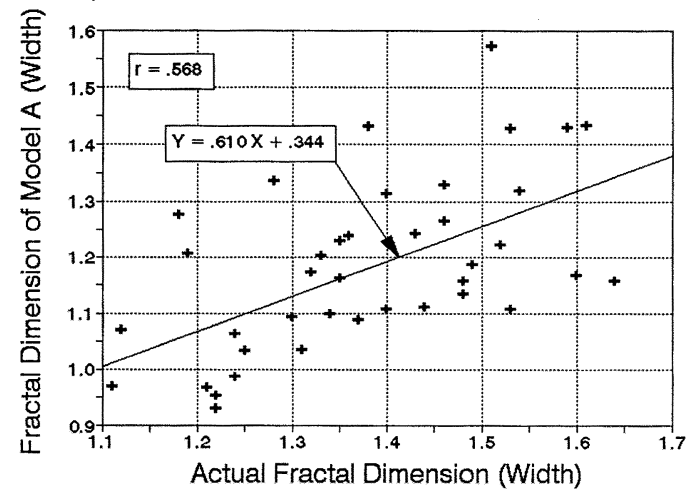

b)

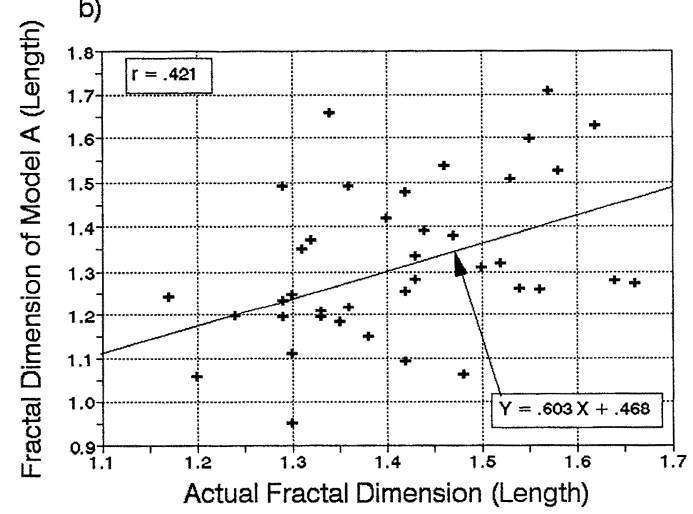

Figure 14 Relationship of fractal dimension of actual landslide and Model $A$ for $a$ ) width and $b$ ) length.

dimension suggests that discontinuities influence the block propagation process. The analysis of the fractal dimension of lineaments revealed that lineaments influence second level block distribution more strongly than third level block distribution. It is considered that different levels of discontinuities influence second level and third level block propagation separately. However, there isn't enough evidence about the influence of discontinuities on third level blocks. The difference between the fractal dimension of second and third level blocks might be due to this difference in their mechanics. Third level blocks are rotational type failures while second level blocks are complex type failures ${ }^{13)}$, i.e., rotational at the head and translational elsewhere. Translational slides are heavily controlled by discontinuities. This process is idealized in Model B, which shows that second and third level blocks develop independently and combined blocks come to have a fractal character. a)
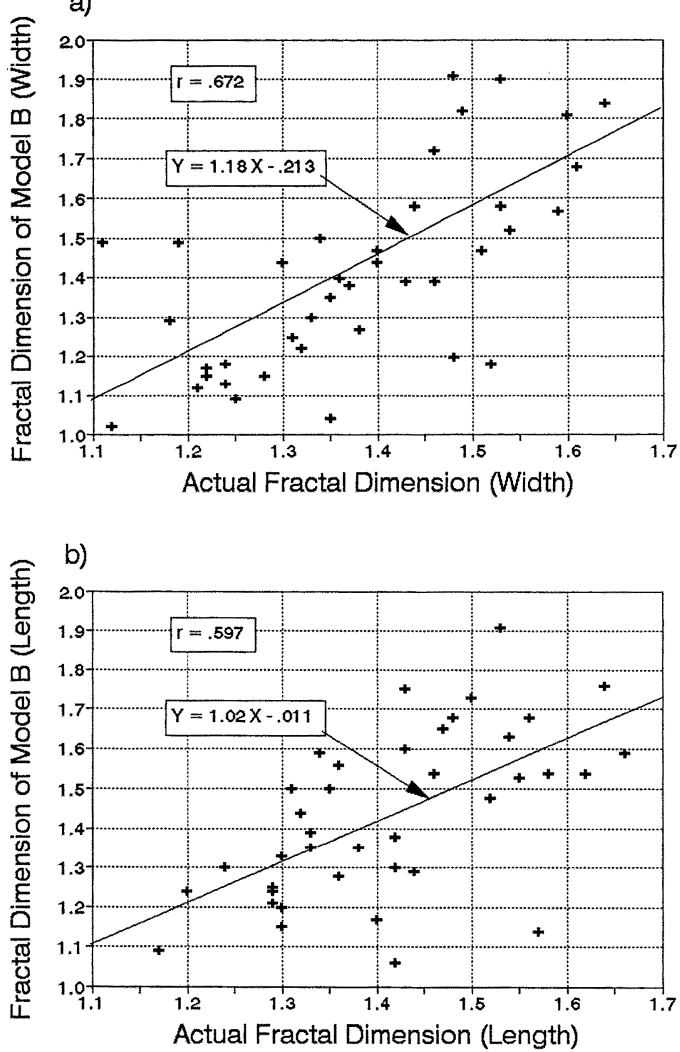

Figure 15 Relationship of fractal dimension of actual landslide and Model $B$ for a) width and $b$ ) length.

Landslide block distribution keeps its fractal character during the process of erosion, because erosion is also a fractal process. As erosion progresses, the absolute value of the slope of the $\log (N(r))$ versus $\log (r)$ plot, which is equivalent to the fractal dimension, decreases (Figure 12). The fractal dimension can be an index of activity or time passed since block propagation stopped.

The block propagation process of landslides can be summarized as follows (Figure 16):

Stage 1: Initial (first level) slide occurs as a huge block.

Stage 2: Second level blocks occur inside the initial block. They are controlled by the geometry of the initial block and by lineaments (discontinuities). Second level block distribution has a unique fractal dimension, which relates to the fractal dimension of the lineaments.

Stage 3: Third level blocks occur mainly inside the second level blocks. They are controlled by 


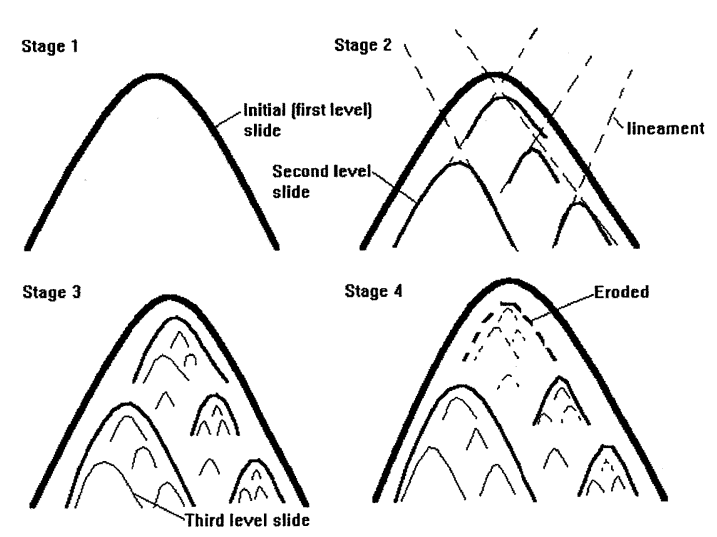

Figure 16 Conceptual landslide development process. (see text for explanation)

the geometry of the second level blocks, by outcrop size fractures and/or by cohesion and friction of the soil. Third level block distribution has another unique fractal dimension.

Stage 4: Erosion starts where activity has finished. Block distribution keeps its fractal character during erosion; however, the fractal dimension decreases in proportion to the degree of erosion.

\section{Conclusion and further study}

The fractal characteristics of landslide block distribution were analyzed and the block development process was discussed using its fractal character. The results can be summarized as follows:

Fractal dimension correlates to the geometry of the landslide, discontinuities of the base rock, and activity level of the landslide. Fractal dimension is independent of the size of the landslide, angle of the slide surface, and geology of the base rock.

The self-similar (fractal) character of landslide blocks can be explained by the influence of block geometry on block propagation (a preceding block to subsequent blocks) (Model A). The unique fractal dimension of second and third level blocks is explained by the influence of different levels of discontinuities or different mechanisms (Model B).

The activity level of landslides correlates to the fractal dimension. Activity was defined in this paper as time period passed since block propagation ended. As erosion progresses, the fractal dimension of the landslide block distribution decreases.
Landslide block distribution has a multiple level character ${ }^{2)}$.This multiple level character was developed by the self-similar (fractal) process and influence of lineaments, which themselves have fractal distribution.

The block propagation process was analyzed using two kinds of models. However, the erosional process, which also influences fractal dimension, was analyzed only in terms of time. The degree of erosion depends on its energy, the resistance (strength) of the soil, and length of time. A proper model for erosion, taking into consideration its energy and the resistance of the soil, would help in better understanding the fractal character of landslide block distribution.

Recognizing landslides, especially huge dormant or stable ones, is an important and basic task for a geotechnical engineer; it is also a difficult one. Even an experienced engineer sometimes misses recognizing the landslides. We hope that knowledge of landslide block distribution patterns, which is fractal geometry, will help in identifying potential landslides.

Acknowledgment We thank Dr. Nobuyuki Takahama, Niigata University; Public Works Research Institute, Ministry of Construction of Japan; and Hokuriku Agricultural Administration Office, Ministry of Agriculture, Forestry, and Fisheries of Japan for sharing unpublished data with us.

\section{References}

1) HIGAKI, D.; UENO, T., and YOSHIMATSU, H. (1994) : Progress level and fractal evolution of landslide slopes, Proceedings of the Seventh International Symposium on Landslides, Lausanne, Switzerland, A. A. Balkema, Rotterdam. pp. $83-88$.

2) TAKAHAMA, N. and ITO, Y. (1989) : Relation between ancient primary landslides and present landslides - Level and history of landslide activities-, Annual Report of Saigai-ken, Niigata University, Japan, No. 11. pp. $25-$ 36. ${ }^{*}$

3) YOKOI, Y.; CARR, J. R.; and WATTERS, R. J. (1995) : Fractal character of landslides, Journal of Environmental and Engineering Geoscience, Vol. 1, No. 1, pp. $75-81$.

4) CARR, J. R. and WARRINER, J. B. (1989) : Relationship between the fractal dimension and joint roughness coefficient, Bulletin of the Association of Engineering Geologists, Vol. 26, No. 2, pp. $253-263$.

5) SASAKI, Y.; ABE, M.; and HIRANO, I. (1991) : Fractal of slope failure size-number distribution, Journal of the Japan Society of Engineering Geology, Vol. 32, No. 3, pp. $1-11 .^{*}$

6) AMERICAN GEOLOGICAL INSTITUTE (1976) : Dictionary of Geological Terms, Anchor Press, Garden City, New York, 472 p. 
7) PEITGEN, H.-O.; MALETSKY, E.; PERCIANTE, T. H.; and YUKKER, L. E. (1992) : Fractal for Classroom, Vol. 1, Springer - Verlag, New York, $450 \mathrm{p}$.

8) OLSON, S. G. and CARR J. R. (1990): Correspondence analysis of water quality data: implications for fauna deaths at Stillwater Lakes, Mathematical Geology, Vol. 22 , No. 6 , pp. $665-698$.

9) CARR, J. R. (1990) : CORSPOND: a portable FORTRAN-77 program for correspondence analysis, Computer and Geosciences, Vol. 16, No. 3, pp. $289-307$.

10) DAVIS, D. C. (1986) : Statistics and Analysis in Geology, John Wiley and Sons, New York, $646 \mathrm{p}$.

11) CARR J. R. (1994) : Numerical Analysis for the Geological Sciences, Prentice Hall, Englewood Cliffs, NJ, 592 p.

12) DAVORE, J. L. (1987) : Probability and Statistics for Engineering and the Sciences, Cole Publishing Company, Monterey, California, $672 \mathrm{p}$.

13) VARNES, D. J. (1998): Slope movement types and processes, In: Landslides: Analysis and Control, Transportation Res. Board Nat. Ac. Sci. Washington Spec. Rep. 176, pp. $11-33$.

14) GATES, W. C. B. (1994) : Regional Slope Stability of the Truckee River Canyon (Drainage Basin) from Tahoe City, California to Reno, Nevada, unpubl. Ph.D. thesis, Mackay School of Mines, University of Nevada, Reno, $380 \mathrm{p}$.

15) VONDER LINDEN, K. and LINDVALL, C. E. (1982) : The Portuguese Bend Landslide, In Cooper, J. D. (editor): Landslide and Landslide Abatement, Palos Verdes Peninsula, Southern California, Assoc. of Engineering Geologists, Southern California Section, Anaheim, pp. 49 56 .

16) OLSHANSKY, R. B. (1990) : Landslide Hazard in the United States: Case Study, Garland Pub., New York, 63 p.

17) SCHRODER, J. F. (1971) : Landslide of Utah, Utah Geological and Mineralogical Survey, Bulletin 90, pp. 1-51.

18) VOIGHT, B. (1978) : Lower Gros Ventre Slide, Wyoming, U.S.A., In Voight, B. (editor): Rockslides and Avalanches, Elsevier Scientific Pub., Amsterdam. pp. $113-166$.

19) DARIN, D. (1993) : The Meadow Mountain Landslide Complex, Eagle County, Colorado, unpubl. MS thesis, Mackay School of Mines, University of Nevada, Reno, $142 \mathrm{p}$.

20) KOJAN, E. and HUTCHINSON, J. N. (1978) : Mayunmarca rockslide and debris flow, Peru, In Voight, B. (editor): Rockslides and Avalanches, Elsevier Scientific Pub.,
Amsterdam, pp. 315 - 361.

21) LEE, K. and DUNCAN, J. M. (1975) : Landslide on April 25, 1974 on the Mantaro River, Peru, National Academy of Sciences, Washington D. C., $71 \mathrm{p}$.

22) BEROCAL, J.; ESPINASA, A. F.; and GALDOS, J. (1978) : Seismological and geological aspects of the Mantaro landslide in Peru, Nature, Vol. 275, pp. 533-536.

23) NOVERRAZ, F. and BORNNARD, Ch. (1988) : Technical note on the visit of La Frasse Landslide: In Bonnard, C. (editor), Proceedings of the Fifth International Symposium on Landslides, Lausanne, Switzerland, A. A. Balkema, Rotterdam, pp. 1549 - 1554.

24) GABUS, J. H.; BONNARD, Ch.; NOVERRAZ, F.; and PARRIAUX, A. (1988): Arveyes, un glissement, une tentative de correction: In Bonnard, C. (editor), Proceedings of the Fifth International Symposium on Landslides, Lausanne, Switzerland, A. A. Balkema, Rotterdam, pp. $911-914 . * *$

25) TAKAHAMA, N.; UDA, T.; NOZAKI, T.; YOKOI, Y.; and SUZUKI, K. (1992): Hazard and environmental geology of northern part of Fossa Magna and southern part of Northeast Japan, Proceeding of 29th IGC Field Trip C16, 33p.

26) HOKURIKU AGRICULTURAL ADMINISTRATION OFFICE, PLANNING DEPARTMENT, RESOURCES DIVISION (1993) : Basic Research on Preservation of Agricultural Land - Report of Special Landslide Mitigation in Hokuriku Region, unpubl. circular, 400 p.***

27) OKUSA, S.;TAKAHAMA, N.; and FUJTA, Y. (1991) : Landslide history in a Tertiary sedimentary basin in Quaternary in Japan, Quaternary Engineering Geology, Geological Society Engineering Geology Special Publication No. 7, pp. $671-677$.

28) TAKAHAMA, N. and HAYAKAWA, K. (1994): Presently active landslides in ancient primary slide mass at Higashinomyo, Niigata, Central Japan, Journal of Japan Landslide Society, Vol. 31, No. 3, pp. 16-23.*

29) JAPAN LANDSLIDE SOCIETY, KANSAI BRANCH (1988) : History of Investigation of Nishinotani Landslide, Ehime Prefecture, Proceedings of Field Discussion of Japan Landslide Society, Kansai Branch, p. 76. ${ }^{* * *}$

\footnotetext{
*: in Japanese with English abstract

** : in French with English abstract

*** : in Japanese
}

(1995年 8 月 7 日受付，1995年12月20日受理） 
Appendix: Landslide Data List

\begin{tabular}{|c|c|c|c|c|c|c|c|c|c|c|c|c|c|}
\hline \multirow[t]{2}{*}{ No. } & \multirow[t]{2}{*}{ Landslide } & \multirow{2}{*}{\begin{tabular}{|l|} 
Area \\
$(\mathrm{Km} 2)$ \\
\end{tabular}} & \multirow{2}{*}{\begin{tabular}{|l} 
Location \\
$*$ \\
\end{tabular}} & \multirow[t]{2}{*}{ Geology** } & \multicolumn{7}{|c|}{ Fractal Dimension (D)*** } & \multirow{2}{*}{\begin{tabular}{l|} 
Investigation \\
$* * * *$ \\
\end{tabular}} & \multirow[t]{2}{*}{ Reference } \\
\hline & & & & & $D(m)$ & $D\left(w_{2}\right)$ & $D(w 3)$ & $D(1)$ & $D(12)$ & $D(13)$ & $D(\operatorname{Lin})$ & & \\
\hline & Midway Bridge & 4. 8 & $\mathrm{CA}$ & T. and & 1.53 & 2.77 & 3.27 & 1.42 & 1.79 & 2.90 & 1.637 & F, A, M, L & 14) \\
\hline & Boca Ridge & 13.7 & $\mathrm{CA}$ & T. latite, dia & 1.33 & 1.49 & 3.62 & 1.29 & 1.35 & 3.01 & 1.564 & F, A, M, L & 14) \\
\hline 3 & Palos Verdes & 10.7 & CA & T. ss, ms, bas & 1.48 & 1.84 & 2.21 & 1.57 & 2.59 & 2.08 & 1.795 & F. A. M. L & 15) \\
\hline & Big Rock Mesa & 1.2 & $\mathrm{CA}$ & T. ss, ms & 1.48 & 1.86 & 3.39 & 1.53 & 1.63 & 3.37 & 1.747 & F, A, M. L & 16) \\
\hline & Thristle & 11.2 & Utah & M. ss, sh, cong & 1.32 & 1.31 & 2.13 & 1.29 & 1.15 & 2.08 & 1.690 & A, M, L & 16) 17$)$ \\
\hline & Lower Gros Ventre & 8.8 & Hyoming & M. sh, dol, ss & 1.28 & 1.30 & 2.17 & 1.17 & 1.62 & 2.89 & & M. L & 18) \\
\hline & Upper Gros Ventre & 19.8 & Wyoming & II. sh, dol, ss & 1. 30 & 1.44 & 3.51 & 1.20 & 1.36 & 2.05 & 1.703 & A. M & \\
\hline 8 & Meadow Mt. & 1.5 & Colorado & H. $\mid$ im, ss, shl & 1.43 & 2.15 & 3.41 & 1.24 & 1.48 & 2.41 & & M, L & 19) \\
\hline & Mayunmarca & 25.2 & Peru & M. ss, sh & 1.52 & 1.64 & 2.31 & 1.40 & 2.10 & 2.02 & & $L$ & 20) 21) 22) \\
\hline 10 & La Frasse & 1.7 & Swt. & M. schist & 1.59 & 2.13 & 3.57 & 1.36 & 2.11 & 3.49 & & $L$ & 23) \\
\hline 11 & Arvey & 1.3 & Swt. & I. schist & 1.24 & 1.58 & 2.24 & 1.42 & 1.54 & 2.33 & & $L$ & 24) \\
\hline 12 & Kiritani（桐谷） & 3.4 & Toyama & T. $t f-b, t f, m s$ & 1.24 & 1.36 & 2.34 & 1.34 & 1.46 & 3.34 & 1.668 & F, A, M & \\
\hline 13 & Katsurabara（桂原） & 1.5 & Toyama & T. tf-b, tf, ms & 1.38 & 1.37 & 1.90 & 1.44 & 1.82 & 2.26 & 1.759 & F, A, M & \\
\hline 14 & Hitohane (一訽) & 3.5 & Toyama & T. $\mathrm{ms}$ & 1.64 & 1.84 & 3.80 & 1.66 & 1.83 & 3.96 & & F, A, M & \\
\hline 15 & Takisaka（渀坂） & 1.3 & Fukushima & T. $t f$ ms & 1.36 & 1.57 & 2.86 & 1.30 & 1.44 & 3.02 & 1.717 & M. L & 25) \\
\hline 16 & Sakae (栄) & 3.3 & Ni igata & T. ms & 1.12 & 1.22 & 2.41 & 1.42 & 2.36 & 2.00 & & L & 2) 26$)$ \\
\hline 17 & Mushigame (虫畳) & 4.5 & Ni igata & T. ms & 1.31 & 1.72 & 3.17 & 1.56 & 1.67 & 2.59 & 1.711 & M. L & 26) 27) \\
\hline 18 & Higashinomyo（東野名） & 2.5 & Ni igata & T. $\mathrm{ms}$ & 1. 22 & 1.51 & 2.88 & 1.29 & 1.58 & 2.56 & & $L$ & 26) 28) \\
\hline 19 & Karuizawa (軽井沢) & 5.7 & Ni igata & T. ms & 1.61 & 2.30 & 3.29 & 1.43 & 1.82 & 3.08 & 1.701 & M. L & 26) \\
\hline 20 & Happoudai (八方台) & 4.0 & Ni igata & T. $\mathrm{ms}$ & 1.35 & 1.78 & 2.63 & 1.46 & 1.73 & 3.25 & 1.685 & M. L & 26) \\
\hline 21 & Raiden (来伝) & 5.0 & Ni igata & T. ms & 1.53 & 2.03 & 3.16 & 1.48 & 1.85 & 3.19 & 1.736 & M. L & 26) \\
\hline 22 & Nishinakanomata (西中野俣) & 2.9 & Ni igata & T. ms & 1.51 & 2.09 & 3.53 & 1.35 & 2.00 & 3.32 & 1.715 & M. L & 26) \\
\hline 23 & Mizunashi（水梨） & 3.3 & Ni igata & T. ms, tf & 1.60 & 1.84 & 3.27 & 1.64 & 2.60 & 3. 18 & & M. $L$ & 26) \\
\hline 24 & Kitaurata（北浦田） & 3.4 & Ni igata & T. ms & 1.19 & 1.13 & 3.95 & 1.43 & 1.41 & 4.17 & 1.710 & M. L & 26) \\
\hline 25 & Uenoyama (上の山) & 1.1 & Ni igata & T. ms, ss & 1.25 & 1.34 & 2.45 & 1.32 & 1.38 & 3.50 & & M. L & 26) \\
\hline 26 & Nakatateyama（中立山） & 3.2 & Ni igata & T. tf & 1.44 & 1.96 & 2. 89 & 1.58 & 2. 68 & 2.99 & & M. L & 26) \\
\hline 27 & Yumoto (湯本) & 1.3 & Ni igata & T. ms, tf & 1.40 & 1.41 & 3.41 & 1.30 & 1.86 & 3.00 & & M, L & 26) \\
\hline 28 & Yuyama（湯山） & 2.8 & Ni igata & T. ms, tf & 1.40 & 2.15 & 3.50 & 1.47 & 1.89 & 4. 14 & & M. L & 26) \\
\hline 29 & Kamatsuka (釜塚) & 2.7 & Ni igata & T. ss, ms & 1.46 & 1.96 & 2. 49 & 1.55 & 1.94 & 2. 28 & & M. L & 26) \\
\hline 30 & Maruyana（丸山） & 9.0 & Ni igata & T. ss, cong & 1.34 & 1.45 & 2.92 & 1.33 & 1.65 & 2.77 & & M. L & 26) \\
\hline 31 & Maseguchi（棚口） & 3.9 & Ni igata & T. ms & 1.49 & 1.39 & 3.56 & 1.54 & 1.53 & 3.15 & 1.665 & M. L & 25) 26$)$ \\
\hline 32 & Maruta（丸田） & 6.9 & Ni igata & T. ms, ss & 1.37 & 1.46 & 3.58 & 1.36 & 1.83 & 3.50 & 1.643 & M. L & 26) \\
\hline 33 & Kodomari（小泊） & 4.2. & Ni igata & T. ms, ss & 1.21 & 1.29 & 3.42 & 1.38 & 1.43 & 2.88 & & M. L & 26) \\
\hline 34 & Ohbora（大洞） & 6.1 & Ni igata & T. ms, ss, tf & 1.18 & 1.39 & 2.34 & 1.33 & 1.63 & 2.39 & & M. L & 2) 26$)$ \\
\hline 35 & Urushinose（漆野瀬） & 0.3 & Tokushima & I. schist & 1.11 & 1.33 & 3.24 & 1.31 & 1.76 & 3.11 & & F, $M$ & \\
\hline 36 & Nishinotani（西の谷） & 1.0 & Ehime & M. ss, ch, lim & 1.54 & 2.09 & 2.82 & 1.52 & 2.00 & 2.65 & & F, M. L & 29) \\
\hline 37 & Youne (八腩) & 1.0 & Kouchi & M. greenstone & 1.35 & 1.77 & 2.71 & 1.62 & 2.11 & 2.29 & 1.745 & M. L & 1) \\
\hline 38 & Nuta (怒田) & 2.9 & Kouchi & M. greenstone & 1.46 & 1.58 & 3.46 & 1.50 & 1.47 & 3.24 & & M. L & 1) \\
\hline & Nyuuya (入谷) & 1.2 & Nagano & II. schist & 1.22 & 1.73 & 2.65 & 1.30 & 1.79 & 2.77 & 1.647 & M. L & 1) \\
\hline & Average & 4.9 & & & 1.38 & 1.68 & 2.99 & 1.41 & 1.78 & 2.90 & 1.697 & & \\
\hline & Standard 'deviation & 5.20 & & & 0.14 & 0.36 & 0.55 & 0.12 & 0.36 & 0.57 & 0.053 & & \\
\hline
\end{tabular}

* CA: California, Swit: Switzerland

** T: Tertiary, M: Mesozoic, ss: sandstone, ms: mudstone, cong: conglomalate, dia: diatomite, dolo: dolomite, lim: Iimestone tf-br: tuff bressia, bas: basalt, sh: shale, ch: chart

*** $D(w): D$ of width of whole blocks, $D(w 2): D$ of width of 2nd level blocks, $D(w 3): D$ of width of 3rd level blocks $D(I): D$ of length of whole blocks, $D(\mid 2): D$ of length of 2nd level blocks, $D(\mid 3): D$ of length of 3rd level blocks $D($ Lin) : $D$ of lineaments

**** F: field investigation, A: aerial photo interpretation, $M$ : map interpretation, L: literature 